villi in folate-deficient alcoholics, ${ }^{56}$ and ultrastructural changes similar to those found in the liver have been seen on electron microscopy. ${ }^{7} \mathrm{~A}$ direct toxic effect on the small bowel, however, is unlikely to explain ileal dysfunction (as shown by defective absorption of vitamin $\mathrm{B}_{12}$ ), since alcohol is rapidly and completely absorbed in the upper gut. Both oral and intravenous alcohol cause a sharp fall in mixing (type I) contractions in the jejunum and an increase in propulsive (type III) waves in the ileum when given to either chronic alcoholics or healthy volunteers. ${ }^{8}$ An indirect stimulant action either of alcohol or its metabolites is therefore possible.

An increasingly recognized accompaniment of alcoholism is folate deficiency, and this may be a cause of malabsorption in some patients, since the defect can be cured by providing folate supplements even though intake of alcohol is continued. ${ }^{4}$ Protein deficiency may be another. A pattern of excessive loss of fat and nitrogen with normal levels of $D$-xylose and vitamin $B_{12}$ may be found, suggesting pancreatic insufficiency, and half of a group of patients studied by Mezey et al. ${ }^{3}$ had defective pancreatic function as judged by the results of a secretin test. In some this could be reversed by increasing protein consumption in spite of continued intake of alcohol, while in others the lack of response was attributed to irreversible damage to the pancreas (though there were no symptoms of pancreatitis). Alcohol ingestion does not apparently directly affect pancreatic function, and the malabsorption may be due to dietary protein lack; similar effects on pancreatic function have been seen in kwashiorkor and adult malnutrition.

Diarrhoea in the alcoholic may be due to structural changes in the small or large bowel, in the pancreas, or in the liver. It may result from interference in gastrointestinal function, altering motility or causing an imbalance of fluid, electrolyte, and nutrient absorption. It may be secondary to dietary deficiencies of protein, folate, and possibly other essential substances. In the individual patient it is necessary to try and unravel these different mechanisms in order to find the right treatment.

\footnotetext{
1 Small, M., Longarini, A., and Zamcheck, N., American fournal of Medicine, $1959,27,575$.

Roggin, G. M., et al., fohns Hopkins Medical fournal, 1969, 125, 321.

3 Mezey, E., et al., Gastroenterology, 1970, 59, 657.

Halsted, C. H., Robles, E. A., and Mezey, E., Gastroenterology, 1973, 64, 526.

5 Bianchi, A., et al., New England fournal of Medicine, 1970, 282, 859.

- Hermos, J. A., et al., Annals of Internal Medicine, 1972, 76, 957.

7 Rubin, E., et al., Gastroenterology, 1972, 63, 801.

8 Robles, E. A., et al., fohns Hopkins Medical fournal, 1974, 135, 17.
}

\section{Genitourinary Medicine}

During the past 25 years there has been a great expansion of the venereal diseases service in Britain. Not only has the number of new cases increased more than threefold, so that in 1973 more than 360000 cases were seen at the clinics, but the type of disease diagnosed has also changed radically. Syphilis and gonorrhoea, the two conditions for which the clinics were originally instituted 58 years ago, now account for less than $25 \%$ of the cases diagnosed, and most of the work is concerned with other sexually transmitted diseases and conditions which arise as a result of sexual activity or affect the genitourinary tract. In the more progressive centres the breadth of the specialty has increased steadily and it now includes a wide spectrum of medical problems.
In Britain and several other western countries patients who develop symptoms after sexual activity usually seek out a clinic for sexually transmitted diseases and do not go to their general practitioners. The clinics are staffed by doctors, nurses, social workers, technicians, and other workers who have received special training in the subject. They have at their disposal specialized diagnostic equipment as well as the knowledge and experience of how to interpret the results. Contact tracers, working in the clinics in close collaboration with the doctors, play a major role in the control of the incidence of the diseases by helping the patients with their contacts and also reminding defaulters who have not completed their treatment or follow-up. Arrangements are usually available for patients with personal, family, social, or financial problems to receive help from a medical social worker, and in a few centres a psychiatrist attends the clinic for one or two sessions a week. The grouping of infectious diseases of the genital and urinary tracts together in one specialty also facilitates teaching of the subject to undergraduate and postgraduate students and is a stimulus for research.

Over the years the facilities for treatment of sexually transmitted disease in Britain have become the most highly developed in the world, and foreign postgraduate students and workers frequently visit the larger centres. Furthermore, the British Postgraduate Medical Federation now organizes a successful postgraduate course in sexually transmitted diseases twice a year.

A recent publication ${ }^{1}$ by the Office of Health Economics points out that the United Kingdom has a lower rate of syphilis and gonorrhoea per 100000 population than any other comparable industrial country and suggests that, at approximately $£ 5$ million per annum, the cost-effectiveness of the service is satisfactory. However, the report points out that there would be many advantages if the specialty of venereology could be broadened to include a wider range of genitourinary disorders and the name changed to genitourinary medicine.

Those who would benefit most from such a change are the patients themselves, as most of them do not have a venereal disease in the old legal sense of the term. It would, therefore, help to remove some of the social stigma of attending a clinic, make it easier for general practitioners to refer patients with genitourinary symptoms, and encourage more young doctors to make a career in the specialty. It has been apparent to a minority of those working in the field for several years that as the subject has evolved the older names for the specialty were too narrow and terms such as V.D. clinic or special clinic had become increasingly inappropriate. The term sexually transmitted diseases may be satisfactory to describe the diseases themselves but is unsatisfactory for the name of the department, the specialty itself, and the doctors who work in it.

Genitourinary medicine accurately describes the work now carried out in the clinics and has no emotional or judgemental overtones. There should be no confusion with urology, which is a surgical specialty concerned with the same anatomical areas, just as cardiology is not confused with cardiac surgery or neurology with neurosurgery. The new name simply acknowledges a situation which already exists and is part of the redefinition of medical specialties which has been occurring during the past decade in such subjects as rheumatology and communicable diseases. As a result of the change the work of genitourinary physicians could expand to include infertility and other diseases of the genitourinary tract when appropriate. New departments would be situated in the general outpatient concourse and not be physically isolated as many are still today. In this regard it is interesting to note that at the St. Louis Hospital in Paris the name of the department had to be changed 
last year at the insistance of the patients to "Medècine Urogenital."

The name genitourinary medicine has been approved by the Royal College of Physicians of London and the title of the adviser in venereology to the Department of Health and Social Security has been changed to adviser in genitourinary medicine. Already several teaching hospitals have adopted the name for their departments. At the Middlesex Hospital Medical School the academic board has approved a proposal that a chair in genitourinary medicine be established if funds to finance it can be found. As the specialty develops and its practitioners increase in number the use of the name will spread. The most important reason for its universal adoption in Britain is for the sake of the patients, and this consideration should have top priority in everybody's mind. It could do much to remove guilt, fear, stigma, and emotional distress from a large number of patients attending Britain's hospitals.

1 Venereal Disease. Office of Health Economics Briefing, no. 1. London, O.H.F., 1974 .

\section{Jam Tomorrow?}

Just 15 years ago Sir Harry Pilkington and his colleagues on the Royal Commission finished their three-year study of N.H.S. doctors' and dentists' pay. ${ }^{1}$ Their recommendations prepared the foundation for the many reviews of the two professions' remuneration carried out since then. Unhappily two of that report's important concepts-the need for an independent referee between the Government and the profession and the advice that pay should not "be determined by consideration of political convenience"-have recently taken a severe buffeting.

Firstly, the referee's independence has been curtailed by statutory pay policies. Secondly, despite Mrs. Barbara Castle's admission that after 25 July there were no legal restraints on doctors' incomes, ${ }^{2}$ the Review Body has chosen in its latest report (p. 104) to take cover behind Government policy-the social contract. Will this prompt more doctors to ask whether the review body procedure has outlived its usefulness? Certainly a nil award for most N.H.S. doctors will do nothing to halt the decline of the N.H.S. The B.M.A.'s Joint Evidence Committee, meeting "to consider the very serious position of doctors' pay," has recommended to its constituent committees "that an early meeting should be sought with the Prime Minister."

A near-catastrophic rate of inflation and the severe effect of the counter-inflation legislation on the professions' incomes were seen by the Joint Evidence Committee as compelling reasons for demanding an interim award so soon after an "annual" report. ${ }^{3}$ But "jam tomorrow" is the only message in this supplementary report. Apart from a $13.6 \%$ award to certain ex-public health doctors (whose pay was being reviewed for the first time since October 1973) N.H.S. doctors will receive no addition to their incomes though the Review Body's own revised figures show that on 1 April 1974 N.H.S. doctors' incomes as a whole were already $11 \%$ behind the 1972 comparison. So between 1 April 1972 and 31 March 1975 a general practitioner or consultant will have lost a very substantial sum of money-even before taking account of the $18 \%$ inflation rate forecast for 1974-5.

Well, isn't this what incomes restraint is about and shouldn't doctors as a responsible group accept this unpalatable decline in living standards in the national interest? Possibly they might if the profession thought that the "incomes' policy" was being applied fairly throughout society. But to many doctors it will seem that once again they are being used as an economic regulator-in contrast to other groups whose pay increases have escaped the social contract.

Even if few N.H.S. doctors were expecting realistic increases in their incomes general practitioners had looked forward to some respite in battling with their ever-mounting practice expenses. An average increase in practice expenses of $£ 145$ (backdated to 1 April 1974) taken with the April award will bring the percentage rise for expenses for the year to just over $20 \%$-more than the official figures for inflation. Nevertheless, with reports of some doctors contemplating the restriction of home visits because of motoring costs and of others paying back income into the practice fund to meet expenses they are obviously very worried. Family doctors' net incomes and their expenses have, particularly since 1964, been closely interrelated, and their difficulties over meeting the latter may well be because they do not realize the extent to which their real incomes have fallen behind since 1972 . Whatever the reasons general practitioners are feeling the effects of inflation. How many of them will not stay to find out whether the Review Body's promise for substantial increases in 1975 materialises ? How many will look back and ask whether the lessons of 1964 have been forgotten?

Much of the discontent among hospital doctors results from trying to run a comprehensive hospital service on insufficient resources, though they too are unhappy about pay. With consultants now confronting Mrs. Castle over their contract reforms (4 January, p. 4) and the juniors threatening to follow suit (p.110) is the time near when all N.H.S. doctors will unite to make the Government face up to the future of the N.H.S. ?

The staff unrest throughout the whole N.H.S. stems mainly from the Service's chronic underfinancing. It will continue until the country recognizes that a finite money supply means a finite limit to medical facilities. Britain spends less per head on health than most other European countries-while boasting that it provides the most comprehensive health service of the lot. The profession could constructively channel some of its growing militancy to convincing the country and the Government of these simple facts.

' Royal Commission on Doctors' and Dentists' Remuneration 1957-1960, Report. Cmnd. 939. H.M.S.O., London, 1960.

2 British Medical fournal, 1974, 3, 479.

3 British Medical fournal, 1974, 2, 124.

The Knighthood conferred on Dr. Ronald Gibson in last week's New Years Honours (see p. 102) will give particular pleasure to his many friends within the Association-and to many others besides. Quite apart from his distinguished work for the B.M.A. itself as Chairman of its Council for six years and in other capacities, he has served both Medicine and his country tirelessly and without stint. He embodies the highest traditions of family doctoring. 